\title{
A EXPECTATIVA DOS PAIS QUANTO À ALFABETIZAÇÃO NA EDUCAÇÃO INFANTIL
}

\section{Ludmylla Karinne Trigueiro Meireles ${ }^{1}$}

\section{Apresentação}

Minha formação em Pedagogia me possibilitou percorrer diversos caminhos na educação desde minha Educação Escolar, passando pela Educação Social para chegar à Iniciação Cientifica, durante os anos de graduação. Considero que cada uma dessas experiências contribuiu para que hoje eu me dedicasse às minhas práticas com um olhar atento às questões que envolvem o ensino, 0 desenvolvimento e a aprendizagem.

Como professora de Educação Infantil, percebo que quando nos remetemos ao tema "escola", o tema da "alfabetização" é também referido ou lembrado com relevância, mesmo no contexto do segmento da E.I., no qual não necessariamente se deve alfabetizar. Em um certo momento, passou a chamar minha atenção o quanto os responsáveis das crianças da instituição em que atuo destacam esse assunto, levando fortemente suas expectativas para a escola. Eles buscam compreender as metodologias utilizadas para uma alfabetização considerada, tanto pelos professores como pelos coordenadores, como precoce.

Com este trabalho, pretendo discutir o tema da alfabetização presente como responsabilidade curricular desde a Educação Infantil e a construção de possibilidades para que este processo possa fluir, respeitando o tempo de aprendizagem e as necessidades da criança.

Levanto alguns posicionamentos afirmados pela equipe pedagógica desta instituição em que trabalho, em relação às perspectivas dos responsáveis quanto à leitura e escrita convencional das crianças. Durante o período de 1 ano e 2 meses (entre fevereiro de 2016 e março de 2017), foi possível participar das vivências escolares das crianças, reuniões de pais, supervisões pedagógicas de professoras (da mesma faixa etária) e Centro de Estudos. Em todos estes momentos, pude observar os frequentes relatos dos profissionais sobre o processo de evolução de leitura e escrita das crianças e suas hipóteses, comentários sobre a avaliação dos responsáveis quanto ao ensino, suas angústias em relação às etapas do processo e o tempo de aprendizagem da criança. A partir deste

1 Graduada em Pedagogia pela Universidade Vale do Rio doce- Univale, Pós Graduada em Psicopedagogia pela Universidade do Estado do Rio de Janeiro - UERJ, integrante do curso de extensão EPELLE na Universidade Federal do Rio de Janeiro - UFRJ e Professora de Educação Infantil da rede privada. meireleslkt@gmail.com 
levantamento, com vistas a produzir uma análise destes aspectos, em sua relação com a questão principal indicada no título, busquei em leituras sobre as concepções de linguagem escrita de Vigotski (2007 e 2008) e ainda com Emília Ferreiro (2001), compreender conceitualmente a metodologia proposta pela escola e o trabalho do professor, em consonância com tempo de maturação da criança, para que a aprendizagem se concretize. Em minha prática pedagógica associada ao projeto de turma, procurei alternativas em que as crianças se sentissem seguras para se arriscarem em novos desafios no intuito de avaliar seus avanços, contemplando os eixos da Educação Infantil. Com a singularidade de cada criança, constatamos que cada uma avançou significativamente em suas condições, como previsto pela equipe pedagógica. No entendimento dos responsáveis, percebemos a satisfação de alguns que confiaram na proposta, embora outros tenham continuado a questionar sobre a leitura e escrita, com receio das exigências do próximo ano escolar.

\section{Caracterização da escola e da turma}

Este estudo teve como campo empírico uma instituição de Educação Infantil da rede privada, situada num bairro da zona sul do Rio de Janeiro, atuando há 35 anos e atendendo um público de classe média alta, de segunda-feira a sexta-feira, de $7 \mathrm{~h}$ (sete horas) às 19h (dezenove horas). Esta instituição acolhe crianças na faixa etária de 0 a 6 anos de idade, organizadas nas turmas de Berçário, Intermediário, Grupo 1, Grupo 2, Grupo 3, Grupo 4, Grupo 5 e, ainda, conta com a turma Integral, visando as necessidades das crescentes demandas sociais da vida familiar moderna.

Os sujeitos a que a pesquisa se refere são crianças que foram selecionadas da turma do Grupo 5 A e B - Tarde, (composta por 15 crianças em 2016 e 12 crianças em 2017) na faixa etária de 5 anos sendo uma especial com 7 anos de idade. Além dos eventos que analisamos, também destacamos os questionamentos sobre a alfabetização dos responsáveis das crianças. As turmas supracitadas me permitiram, além de uma frequente observação, a participação assídua com um contato direto.

Para a realização desta pesquisa, foi necessário observar as práticas vivenciadas em ambiente específico de Educação Infantil, uma vez que é um espaço que oferece possibilidades para as crianças se socializarem, bem como adquirirem e compartilharem suas experiências do dia a dia. Para analisar tal processo, partimos de uma breve apresentação sobre o surgimento da necessidade de instituições especialmente dedicadas à Educação Infantil.

Sendo uma demanda da atualidade, o Referencial Curricular Nacional de Educação Infantil RCNEI (1998) busca justificar a importância da educação de crianças em creches: 
A expansão da educação infantil no Brasil e no mundo tem ocorrido de forma crescente nas últimas décadas, acompanhando a intensificação da urbanização, a participação da mulher no mercado de trabalho e as mudanças na organização e estrutura das famílias. Por outro lado, a sociedade está mais consciente da importância das experiências na primeira infância, o que motiva demandas por uma educação institucional para crianças de zero a seis anos. (RCNEI, 1998, p.11)

Tendo em vista as exigências contemporâneas, percebemos o quanto as mesmas exigem dos órgãos governamentais o estabelecimento da Educação Infantil como um direito da criança, independentemente de sua classe social. O desenvolvimento integral da criança é o que se preza nesse contexto que abrange seus aspectos afetivos, emocionais, sociais e cognitivos.

Realçando a realidade apresentada, escolhemos para análise uma instituição de educação infantil que tem como público alvo crianças da classe média alta, entretanto, o estabelecimento também atende filhos e filhas de funcionários ${ }^{2}$ que lá trabalham, sendo a maioria composta por moradores de comunidades do Rio de Janeiro.

A instituição privada foi fundada na década de 1980, em um contexto histórico em que as lutas sociais e políticas eram frequentes e a participação da mulher no mercado de trabalho crescia a cada dia. A partir dessas vivências, quatro mulheres, sendo três psicólogas e uma administradora, visaram um empreendimento promissor para o momento por estarem motivadas por seus encantamentos e interesses pelo desenvolvimento infantil.

A diretora da creche, que é também uma das fundadoras, explicou as suas intenções e anseios para a abertura do espaço, que é a de garantir um trabalho em que as pessoas percebam o diferencial de sua instituição para oferecer uma educação de qualidade às crianças:

(...) a gente foi atrás de montar uma creche de qualidade. A gente não queria uma creche para os pais deixarem as crianças para ir trabalhar, para mãe ir trabalhar (...) a gente já entra querendo fundar uma escola diferenciada, oferecer um serviço diferenciado para as crianças. A gente já não entendia a C. I. ${ }^{3}$, a creche como um lugar de guarda das crianças e sim um trabalho de desenvolvimento das crianças. Tanto que nós éramos três psicólogas e uma administradora de empresas, nenhuma pedagoga (...). Então a gente queria pensar como é que era o desenvolvimento infantil e as relações entre as crianças e o que a gente poderia fazer para que esse desenvolvimento se desse de uma forma mais... mais... genuína, de uma forma que abrisse a possibilidade para cada criança surgir com a sua singularidade. (...) a gente achou... naquele momento ainda tinha poucas creches, né. A gente... era um mercado promissor nesse sentido assim. Aparentava ser um mercado promissor (...) (Trecho de entrevista realizada em 16 de abril de 2015 com a diretora da C.I). 
Inicialmente, a Psicologia era o diferencial da instituição, pois a equipe, em sua maioria, era composta por professoras que também tinham formação superior nesta área, sendo assim, as fundadoras percebiam que somente cuidar não era o suficiente para expandir as capacidades da criança, e buscaram fundamentos que envolvessem o cuidar e o educar para garantir o desenvolvimento e a aprendizagem infantil. Atualmente, a formação das professoras e equipe coordenadora se divide entre psicólogas e pedagogas. As propostas pedagógicas e curriculares foram elaboradas pela equipe de acordo com as habilidades possíveis de serem alcançadas em cada faixa etária.

Fundamentação teórica

Com frequência, já me aconteceu e acho que deve ser possível presenciar em nosso cotidiano, alguma criança sendo abordada por um adulto, que de forma simpática se aproxima a fim de estender um diálogo, e no bate papo surge a frase: "Você já está na escola?", e dá continuidade a conversa: "E já sabe ler e escrever?".

Certamente isso ocorre por serem comuns as associações entre as palavras "escola" e "alfabetização". Os significados destas palavras estão, de certa forma, conectados pela forma tradicional como a escola é vista, como um local ideal para as instruções sistemáticas de habilidades específicas para ensinar a ler e escrever.

A relevância que se dá à leitura e à escrita em nossa cultura, remete-nos a refletir sobre o fato de já nascermos inseridos em uma sociedade letrada e a alfabetização estar presente em nossas vivências desde o momento em que estamos no mundo, ou seja, a interação com o mundo repleto de informações faz parte do processo de alfabetização.

Ferreiro (2011), conclui que leitura e escrita não são produtos escolares e sim objetos culturais, sendo suporte de ações ou promovendo intercâmbios sociais.

Existem inúmeras amostras de inscrições nos mais variados contextos (letreiros, embalagens, tevê, roupas, periódicos etc.). Os adultos fazem anotações, leem cartas, comentam os periódicos, procuram um número de telefone etc. Isto é, produzem e interpretam a escrita nos mais variados contextos. É evidente que, por si só, a presença isolada do objeto e das ações sociais pertinentes não transmitem conhecimento, mas ambas exercem uma influência, criando as condições dentro das quais isto é possível. Imersa em um mundo onde há a presença de sistemas simbólicos socialmente elaborados, a criança procura compreender a natureza destas marcas especiais. (Ferreiro, 2011, p. 44) 
Tendo em vista esta abordagem, percebe-se que não se trata de um método específico para se ensinar e para aprender. O sistema simbólico, como qualquer outro objeto, é descoberto de forma gradativa, por meio de um processo construtivo. Nas pesquisas de Ferreiro, a autora constatou que algumas crianças conseguem desvendar os princípios do sistema de leitura e escrita antes de iniciarem a vida escolar.

As experiências de produções espontâneas são fundamentais para perceber a elaboração de hipóteses que as crianças vão construindo a partir de ideias influenciadas pelo ambiente. Esta organização mental com critérios organizadores de marcas gráficas, geralmente se dá a partir dos quatro anos de idade onde conseguem distinguir a representação que pode ou não ser lida, como por exemplo, uma figura, que pode ser interpretada se diferencia do conjunto de letras, que pode ser decodificado.

Notam-se os avanços da aprendizagem espontânea, quando é levado em consideração o período em que a criança apresenta o estado de "maturidade" ou de "prontidão" para o processo em questão, tendo o estímulo como condutor rumo ao progresso.

Em consonância com Ferreiro (2011), no que se refere à faixa etária adequada para a sistematização da leitura e escrita, os estudos de Vigotski (2008), especificamente sobre a Zona de Desenvolvimento Proximal (ZPD) podem ser beneficamente relacionados nesta discussão.

A ênfase dada por Vigotski para o interacionismo como item indispensável ao desenvolvimento e à aprendizagem, nos leva a destacar o conceito de Zona de Desenvolvimento Proximal (ZPD). No contato diário com a criança, é fácil identificar quais as atividades que ela já consegue realizar com independência, e quais ela ainda precisa de auxílio colaborativo. Consideramos que o processo de desenvolvimento e aprendizagem desta foi concluído para aquela atividade. A essa capacidade de realizar determinada tarefa sozinho, Oliveira (1997) apresentando a definição de Vigotski, diz ser o nível de desenvolvimento real. Portanto, este termo se refere à fase já alcançada pela criança.

Acompanhando o seu desenvolvimento e sua aprendizagem, além do nível já alcançado, é preciso observar o nível de desenvolvimento potencial, considerado como aquele que ainda precisa da intervenção de alguém que seja capaz de ajudar a criança. A ajuda poderá ser em forma de orientação, demonstração ou qualquer assistência no decorrer da atividade.

Oliveira (1997) salienta que para a criança realizar uma tarefa sozinha ou com intervenção é necessário considerar o seu nível de desenvolvimento. Fatores como capacidades e faixa etária influenciam nesse processo.

Partindo da atuação entre os dois níveis, está a Zona de Desenvolvimento Proximal (ZPD), definida por Vigotski (2008) como: 
(...) a distância entre o nível de desenvolvimento real, que se costuma determinar através da solução independente de problemas, e o nível de desenvolvimento potencial, determinado através da solução de problemas sob orientação de um adulto ou em colaboração de companheiros mais capazes (VIGOTSKI, 2008, p. 97).

As funções psicológicas superiores se fazem presentes nesse processo à medida que o desenvolvimento vai se transformando em aprendizagem, pois com a ajuda de outra pessoa, que tenha maior capacidade, a criança irá conseguir concretizar uma tarefa na qual ainda encontre limitações para, através disso, futuramente, realizá-la sem ajuda. Percebemos aí a importância da interação social que impulsiona o sujeito para o desenvolvimento e a aprendizagem.

\section{Descrição da experiência}

O trabalho enfatizando o processo de alfabetização com a turma de Grupo 5, começou no ano de 2016. A maioria das crianças já iniciou o ano letivo apresentando interesse pela leitura e escrita e animadas com os materiais destinados às tarefas dos exercícios como estojos com lápis de grafite, borracha, apontador e cadernos sem pauta para registros e escrita espontânea.

Nesta perspectiva as intenções pedagógicas, de acordo com a supervisões e estudos da equipe, consistem em possibilitar a comunicação e expressão, aguçando o interesse da criança por conhecer gêneros literários diversos orais e escritos tento o intercâmbio cultural presente nessas situações para que suas vivências pudessem ser valorizadas e discutidas em turma sendo associadas aos projetos de turma e temático de acordo com a proposta curricular da instituição. Além disso, procuramos meios de fazer a criança familiarize-se aos poucos com a escrita por meio de situações as quais ela se faz necessária, como nos livros, embalagens, jornais, revistas e outros.

No intuito de provocar avanços sociais e cognitivos a linguagem foi enfatizada, nas rodas de conversas, apresentação de atividades de casa e debates. Na linguagem escrita, as crianças passaram a conviver em um ambiente repleto de textos.

Neste sentido, buscamos despertar nelas o interesse pelas palavras de forma que compreendessem que a leitura é uma prática de satisfação e que possa Ihe trazer prazer. Partindo deste pressuposto, a curiosidade pela leitura partiu das crianças por meio de diversos materiais escritos que lhes foram oferecidos.

As crianças se envolveram nesse universo e se colocaram disponíveis para trocar conhecimentos com os amigos e adultos expondo suas hipóteses seguindo então para a exploração ativa de experimentação da escrita espontânea e escrita cópia, tento contato com a escrita convencional. 
No primeiro contato com o lápis e caderno para a escrita espontânea, percebemos o receio de iniciar, alegando não saber ler e nem escrever e insistindo que fariam errado. Com o estímulo da professora se sentiram a vontade para se arriscar e perguntavam "Posso fazer do meu jeito?". Esta frase que ficou marcada para a turma que repetia para outros adultos que questionavam o domínio da leitura e escrita convencional lembrando-os : "É do nosso jeito.".

Já seguros para ousarem nos desafios da leitura e escrita, foram oferecidas outras atividades seguindo os passos das práticas de consciência fonológica como jogos de linguagem, escuta e rimas.

\section{Avaliação dos resultados}

Nosso trabalho foi questionado diversas vezes pelos responsáveis das crianças do Grupo 5 , alegando que não compreendiam o sentido da escrita espontânea, uma vez que "não tinha nada escrito, apenas uma sequência de letras aleatórias e sem significados". Sempre que traziam estes argumentos, em reuniões coletivas, individuais, em registro escrito em agendas e em conversas informais com professores e coordenadores, a equipe se disponibilizava para esclarecer nossas intenções de seguir com o processo de alfabetização partindo do conhecimento da criança, estimulando através de brincadeiras, jogos e atividades estratégicas rumo aos avanços deste processo.

A insistência de métodos mais sistematizados de ensinos tradicionais como apresentação da família silábica, soletrar palavra e contornos de pontilhados eram lembrados por eles como métodos eficazes para que chegassem ao fim do ano "aptos" (lendo e escrevendo convencionalmente e realizando letras cursivas) para ingressar no primeiro ano do ensino fundamental.

Nestas situações, demonstramos disponibilidade em atendê-los, expondo as transformações as quais a alfabetização seguiu para que este processo se concretizasse para a criança de forma tranquila e significativa como vem sendo atualizado.

Seguimos o nosso trabalho nos baseando nos estudos de Emilia Ferreiro, Magda Soares e Adams [et al] (2006). Com o tempo, os avanços das crianças surgiram sendo acompanhados pelos seus responsáveis, que nos deu retorno de suas expectativas com tranquilidade e confiança.

Ainda assim, outros responsáveis não se convenceram de nosso trabalho, pois comparavam os avanços das crianças compreendendo que todas deveriam concluir o ano com o mesmo nível de aprendizagem. Em suas justificativas, visavam às exigências das escolas escolhidas para o ano seguinte, no preparo intelectual para a criança efetuar as atividades de forma independente sem pedir ajuda. 
Apesar deste incidente, concluímos que todas as crianças avançaram em seu tempo, levando em consideração o esperado para a faixa etária, a demanda da Educação Infantil, a singularidade de cada um e o respeito aos seus limites e modo de aprender.

\section{Considerações finais}

As exigências de um mundo globalizado, competitivo e repleto de informações instantâneas nos demanda a necessidade de constante atualização e pressa em se destacar no meio social. Essa realidade nos traz anseios de um futuro promissor e quando os pais focam essas expectativas nas crianças, tende a minimizar ou podar a capacidade inventiva das mesmas.

Diante dessa experiência, percebo a importância do cuidado e respeito pela singularidade e aprendizagem, especialmente na Educação Infantil. Na instituição em questão, os estudos e análises referentes às avaliações de seus eixos são discutidas e apontadas pela equipe, levando em consideração as possibilidades de cada um acompanhando as transformações do processo de alfabetização.

Como propõe o nome do Projeto de Turma do Grupo 5 - De mil jeitos, me ajeito - visamos o constante desenvolvimento dos envolvidos munidos de curiosidades. O papel do professor, neste sentido, é estimular a criança para encontrar respostas de seu modo, formulando hipóteses a partir de suas próprias experiências associadas ao que propomos.

Concluímos que a evolução deste processo só acontece quando a criança se sente segura para expressar os seus conhecimentos, refletir sobre suas práticas, debater com os amigos suas hipóteses para chegar a resposta de seus questionamentos.

Referências

ADAMS, Marilyn Jager [et. al]. Consciência fonológica em crianças pequenas. - Porto Alegre: Artmed, 2006.

BRASIL. Ministério da Educação e do Desporto. Secretaria de Educação Fundamental. Referencial curricular nacional para a educação infantil / Ministério da Educação e do Desporto, Secretaria de Educação Fundamental. Brasília: MEC/SEF, 1998. Disponível em: http://portal.mec.gov.br/seb/arquivos/pdf/rcnei vol1.pdf.

FERREIRO, Emilia. Reflexões sobre alfabetização. 26.ed. - São Paulo: Cortez, 2011. 
OLIVEIRA, Marta Kohl de. Vygotsky: aprendizado e desenvolvimento: um processo sócio-histórico. São Paulo: Scipione, 1997.

VIGOTSKI, Lev Semenovich. A formação social da mente: desenvolvimento dos processos psicológicos superiores. L. S. Vigotski; organizadores Michael Cole. [ET al.]; tradução José Cipolla Neto, Luís Silveira Menna Barreto, Solange astro Afeche. 7ạ Ed. São Paulo: Martins Fonte - selo Martins, 2007. (Psicologia e pedagogia)

VIGOTSKI, Lev Semenovitch. 1896-1943. Pensamento e linguagem/ L.S.Vigotski; tradução Jeferson Luiz Camargo; revisão técnica José Cipolla Neto. 4ạ Ed. São Paulo; Martins Fontes, 2008. (Psicologia e pedagogia). 